High Latitude Communications Satellite

By

\author{
Brij N. Agrawal ${ }^{\dagger}$ \\ Naval Postgraduate School \\ Monterey, California
}

This paper presents preliminary design of a high latitude communications satellite. The satellite provides a continuous UHF communications for areas located north of the region covered by geosynchronous communications satellites. The satellite orbit is elliptic with $63.4^{\circ}$ inclination with perigee at $1204 \mathrm{~km}$ altitude in the southern hemisphere and apogee at $14930 \mathrm{~km}$ altitude. The orbit period is 4.8 hours. The system consists of three satellites equally spaced in mean anomaly. It is launched by Delta II launch vehicle in three satellite staked configuration. The spacecraft uses three-axis-stabilization consisting of three reaction wheel system. Solar array surface is always normal to sun rays by spacecraft rotation about yaw axis and solar array drive rotation. The propulsion subsystem is a catalytic monopropellant hydrazine subsystem, consisting of four 38-Newton and twelve 2-Newton thrusters. Electric power is provided by GaAs solar cell and nickel hydrogen batteries.

\title{
INTRODUCTION
}

Geosynchronous spacecraft have been widely used for communications satellites. Three equally spaced geosynchronous spacecraft can provide global communication network. However, geosynchronous spacecraft can not provide communication for high latitude areas. A spacecraft design project was undertaken at the Naval Postgraduate School in Fall 1989 to perform preliminary design of a high latitude communications satellites (HILACS). The paper presents the results of this study including some recent work.

\section{SATELLITE MISSION}

The mission of the satellite system is to provide continuous communications for areas above $60^{\circ} \mathrm{N}$ latitude. The system is shown in Figure 1. The mobile stations (MS) are assumed to be located anywhere above $60^{\circ} \mathrm{N}$ latitude. To link these stations with a geosynchronous satellite, a net control station system (NCS) is located at approximately $60^{\circ} \mathrm{N}$ latitude. A mid-latitude ground station (MLG) system at $40^{\circ} \mathrm{N}$ latitude is used for control of HILACS and geosynchronous satellite and for data transmission.

$\dagger$ Professor, Department of Aeronautics and Astronautics, 


\section{SATELLITE ORBIT AND LAUNCH VEHICLE}

For the satellite mission to provide coverage for area above $60^{\circ} \mathrm{N}$ latitude, a highly elliptical orbit with apogee at northern most point is desirable. This will allow the satellite to stay in high latitude area for longer period of time, resulting in requiring fewer satellites. Orbit elements of an elliptic orbit are shown in Figure 2. Due to sun, moon, and earth oblateness, the orbit parameters will change continuously. For this mission, it is desirable to have apogee at northern most point. Therefore, $\omega$, argument for perigee should be kept within a narrow range. The precession of $\omega$ is give by

$$
\frac{d \omega}{d t}=\frac{-3 n J_{2} R_{e}^{2}}{2 a^{2}\left(1-e^{2}\right)^{2}}\left(\frac{5}{2} \sin ^{2} i-2\right)
$$

where, $\mathrm{n}=$ orbital mean angular rate; $\mathrm{J}_{2}=0.001082 ; \mathrm{R}_{\mathrm{e}}=$ Earth radius; $\mathrm{a}=$ orbit semi-major axis; $\mathrm{e}=$ orbit eccentricity; $\mathrm{i}=$ orbit inclination. For $\mathrm{i}=$ $63.435^{\circ}, \frac{\mathrm{d} \omega}{\mathrm{dt}}=0$.

Therefore, it is preferred to have orbit inclination to be $63.435 \mathrm{deg}$. For the satellite mission, it is desirable to have low perigee altitude and high apogee altitude. Considering the drag effects at too low altitude, perigee altitude is selected to be $1204 \mathrm{~km}$. Next, orbit period/apogee altitude needs to be selected. The orbit period should be sub-multiple of 24 hour. Under this study $4.8,8$ and 12 hours orbit period were initially considered. Because of no significant advantages of 8 hours orbit, 4.8 and 12 hours orbits were only analyzed in depth.

The $4.8 \mathrm{hr}$. period orbit, $1204 \times 14,933 \mathrm{~km}$., can provide full coverage for the entire region north of $60^{\circ} \mathrm{N}$ latitude through the use of three satellites spaced in mean anomaly, with active payload during the portion of the orbit when the satellite sub-satellite point is above $50^{\circ} \mathrm{N}$ latitude. This coverage will require a transmitted beam width (assuming a zero degree elevation angle at the receiver) of 40 degrees at $50^{\circ} \mathrm{N}$ and 35 degrees at apogee. In this configuration, each satellite will remain above 50 degrees North for one hour and 54 minutes of each orbit, providing 18 minutes of overlap during which to spacecraft are in sight of any ground station above this latitude for coordination of the switching of the active satellite. The $12 \mathrm{hr}$ period orbit, 1204 X $3926 \mathrm{~km}$ also known as Molyniya orbit, can provide full coverage requirement through the use of only two spacecraft equally spaced in mean anomaly.

Preliminary mass estimate for the satellite was made. For launch, Taurus, Atlas II and Delta II launch vehicles with orbit $650 \times 850 \mathrm{~km}$ were considered. The $4.8 \mathrm{hr}$ orbit is close to this orbit. However, to place the spacecraft into 12 hour orbit, solid motor with propellant approximately twice the spacecraft mass, will be required. This will increase complexity to spacecraft design and procurement. In addition, three satellite can be launched simultaneously on a single Delta/STAR 48 launch vehicle for 4.8 hour orbit. Based on these considerations, 4.8 hour orbit and Delta II 7925 launch vehicle were selected for the mission. 


\section{Orbit Perturbation}

The drift rate for right ascension of ascending node is given by

$$
\frac{\mathrm{d} \Omega}{\mathrm{dt}}=\frac{3 \mathrm{~nJ}_{2} \mathrm{R}_{\mathrm{e}}^{2}}{2 \mathrm{a}^{2}\left(1-\mathrm{e}^{2}\right)^{2}} \cos \mathrm{i}
$$

For the selected orbit,

$$
\frac{\mathrm{d} \Omega}{\mathrm{dt}}=-0.425 \mathrm{deg} / \mathrm{day} .
$$

The inclination drift rate is periodic in the right ascension of the orbit ascending node which is decreasing daily at the rate of 0.425 degrees. This causes the inclination rate to cycle completely in 847 days with a maximum value of $0.1175 \mathrm{deg} / \mathrm{yr}$ throughout the 3 year lifetime of the satellite.

The Eq.(1) predicts $\mathrm{d} \omega / \mathrm{dt}=0$ for an orbit inclination of $63.435 \mathrm{deg}$. However, due to higher order effects, dw/dt will not be zero. By calculating numerically, the rate is $0.327 \mathrm{deg} / \mathrm{yr}$. The rate is however sensitive to error in this inclination. For an error in inclination of 0.1 degree, the rate becomes 1.44 $\mathrm{deg} / \mathrm{yr}$. The ground coverage of the communications system includes sufficient margin to absorb up to approximately 5 degrees of error in positioning of the perigee. Therefore, for design life time of 3 years, there is no need to budget propellant to correct position of perigee. Since the solar array has the capacity to provide power for a substantial period beyond 3 years, $82 \mathrm{~kg}$ propellant has been budgeted to correct drift of the argument of perigee through four years.

\section{SPACECRAFT CONFIGURATION}

For the spacecraft, several attitude control configurations were considered. Dual-spin spacecraft with spin axis along orbit normal will not be suitable from electric power considerations. In this case the solar angle (angle between solar array normal and sun vector) will vary between $39.9^{\circ}$ and $86.9^{\circ}$ as shown in Fig .3. At winter solstice, the solar array output will be essentially zero. Under three-axis stabilization, fixed momentum wheel system was first considered. In this case the angular momentum will be along orbit normal. Pitch control will make antenna earth oriented. The spacecraft can not be rotated about roll or yaw without external torque, such as by thrusters. In order that the solar arrays to be sun oriented, the solar array drives will have two degree of freedom. Thermal control design will be difficult because all the surfaces will have significant variation in solar flux input. Next, three reaction control system was considered. In this case the spacecraft can be rotated about all three axes without expenditure of propellant. Figure 3 shows coordinate systems. The orbit inclination is $63.4^{\circ}$. XYZ is orbit coordinate system with yaw axis $\mathrm{Z}$ along the vector form the center of mass of the spacecraft to the center of mass of the earth; pitch axis $\mathrm{Y}$ normal to the orbit plane; and roll axis X in the orbit plane with right angle to $\mathrm{Z}$. The spacecraft body fixed coordinate system is $x y z$ and coincides with orbit coordinate system in the absence of attitude angles. As 
shown in Figure 3, the solar array axis is along roll axis. Since the antenna beam is circular global, spacecraft yaw motion will not influence antenna coverage. Therefore spacecraft motion will consist of pitch motion to make antennas earth oriented, rotation $\Psi$ about yaw axis $Z$ to make solar array axis $\mathrm{x}$ normal to sun vector, and rotation of solar array about its axis, $\phi_{\mathrm{s}}$ to make solar array normal to sun vector. The unit vector along $x$-axis, $\vec{i}$, is given by

$$
\overrightarrow{\mathrm{i}}=\overrightarrow{\mathrm{k}} \times \overrightarrow{\mathrm{s}}
$$

where, $\overrightarrow{\mathrm{k}}$ is the unit vector along the yaw axis, $\overrightarrow{\mathrm{s}}$ is the sun vector. The yaw angle $\Psi$ is given by

$$
\psi=\cos ^{-1}(\vec{I} \cdot \vec{i})
$$

where $\vec{I}$ is the unit vector along the roll axis, $x$.

Therefore, for three reaction wheel control system, single degree of freedom solar array drive system is adequate. The east and west surfaces will have zero solar flux input. Therefore these surfaces will be ideal for thermal radiators. The spacecraft configuration is similar to that for a geosynchronous spacecraft. A double gimbal momentum wheel system was also considered. For this system also, the spacecraft can be rotated about all the three spacecraft axes. The spacecraft configuration for this attitude control system is similar to that of three reaction wheel system. Considering complexity and design heritage, three reaction wheel system was selected.

The spacecraft configuration, as shown in Fig. 4, was developed considering the Delta launch vehicle interface constraints, moment of inertia for passive spinstabilization during transfer orbit, use of east and west faces for thermal radiators, and maximizing modularity of subsystems. The basic configuration consists of a center tube with four tanks placed around it, majority of the heat dissipating equipment on east and west surfaces and antennas on the earth surface.

Figure 5 shows earth face panel of the spacecraft, The cross pole antenna is mounted in the center of the panel. The up-link helical antenna is mounted on the northeast corner and down-link antenna on the southwest corner. The earth sensor is mounted centered along the west edge of the earth surface. Figure 6 shows the west face panel which supports all payload equipment. The thermal radiator $(0.7 \mathrm{~m} \mathrm{X} 0.9 \mathrm{~m})$ is centered on the outside surface of the panel. The solar array extends from the center of the panel. The solar array is $0.533 \mathrm{~m}$ wide and $3.576 \mathrm{~m}$ in length and has a $0.85 \mathrm{~m}$ yoke to prevent shadowing of the solar array from spacecraft body. Figure 7 shows the earth face panel. The telemetry subsystem and the electrical power subsystem are mounted on this panel. The thermal radiator is centered on the panel. Extending from the center of the face is a solar array assembly.

Table 1 gives spacecraft mass breakdown. The propulsion system is designed for $140 \mathrm{~kg}$ propellant. For three years design life, as explained earlier, there is no need for propellant for station-keeping. Therefore, only $8 \mathrm{~kg}$ 
propellant will be required. Therefore, this additional $132 \mathrm{~kg}$ propellant can be used for supplementing launch vehicle and/or increased design life. Second alternative is to design propulsion system for only $8 \mathrm{~kg}$ propellant plus $2 \mathrm{~kg}$ margin. This will result in reduction in propellant tank mass and the total spacecraft mass will not exceed $241 \mathrm{~kg}$. The spacecraft mass will be further reduced due to reduction in masses of propulsion and structure subsystems.

TABLE 1 . SPACECRAFT MASS BREAKDOWN

\begin{tabular}{|l|c|}
\hline Subsystem & Mass $(\mathrm{kg})$ \\
\hline Communications Antenna & 3 \\
Communications Transponder & 19 \\
Electric Power & 49 \\
TT\&C & 14 \\
Attitude Control & 17 \\
Propulsion & 35 \\
Structure & 47 \\
Thermal & 15 \\
Electrical/Mechanical Integration & 12 \\
Mass Margin & 20 \\
Spacecraft Dry Mass & 231 \\
Propellant & 7 \\
Transfer Orbit & 82 \\
Perigee Argument & 1 \\
Station Keeping/Attitude Control & 50 \\
Margin & 140 \\
\hline
\end{tabular}

Table 2 gives spacecraft electric power breakdown.

TABLE 2. ELECTRIC POWER REQUIREMENTS

\begin{tabular}{|l|c|}
\hline Subsystem & Power (W) \\
\hline Communications Transponder & 101 \\
TT\&C & 11.0 \\
Attitude Control/Propulsion & 70.0 \\
Thermal & 50.0 \\
Harness & 7.0 \\
Total Load & 259.0 \\
Battery Charge Power & 52.0 \\
Total Sunlight Load & 312.0 \\
Solar Array Margin & 31.0 \\
Total Design Power & 343.0 \\
\hline
\end{tabular}

\section{SPACECRAFT SUBSYSTEMS}

\section{Communications Payload}

The communication system operates at UHF with an up-link frequency of $350 \mathrm{MHz}$ and a down-link frequency of $253 \mathrm{MHz}$. The link will operate at a data 
rate of 4800 bps using coherent BPSK modulation. A linear block error correction coding scheme is used resulting in a coded bit rate of 9600 bps.

The satellite antennas have gains of $3.5 \mathrm{~dB}$ with a transmit power of $20 \mathrm{~W}$ $(13 \mathrm{dBW})$. The receiver's noise figure is assumed to be $2 \mathrm{~dB}$. The antenna for the mobile ground stations are assumed to be of a crossed dipole design with a gain of $3 \mathrm{~dB}$. The receiver's noise figure is $6 \mathrm{~dB}$. The station's transmit power is also assumed to be $100 \mathrm{~W}$. The NCS has two sets of helical array with $14 \mathrm{~dB}$ of gain. The station will require two of these antennas to provide a link with the active descending satellite and with the ascending satellite in preparation for its activation. It will be assumed that this station can transmit with a power of 100 Watts. MLG station will have a high gain helical antenna array with $25 \mathrm{~dB}$ of gain. The transmitter will have a capability of up to $1000 \mathrm{~W}$. The receiver system will have an effective temperature of $150 \mathrm{~K}$.

For the system operation, the required minimum beamwidth is $28^{\circ}$. Such a beam width would correspond to an antenna gain of approximately $15 \mathrm{~dB}$ and a structure too large and too massive for this spacecraft. Since high directivity is not constraint, minimum satellites antenna gain of $2-3 \mathrm{~dB}$ was found to be acceptable from link calculations. For ideal stacking of the satellites on the launch vehicle a maximum separation of $0.3 \mathrm{~m}$ was required. With the tight constraint on the antenna dimensions, the antenna designs chosen to be resonant quadrifilar helix, therefore having an operating bandwidth of approximately $4 \%$. A separate antenna was required of the up-link and down-link. Additionally, a third antenna of crossed dipole design was designed to operate on both frequencies for the telemetry. It is composed of two orthogonal, center fed, half-wavelength antennas. The antenna is sized for the down-link frequency of $253 \mathrm{MHz}$ for a length of $0.593 \mathrm{~m}$. It has a resonating circuit, which electrically shortens the antenna for the higher up-link frequency of $350 \mathrm{MHz}$ or $0.429 \mathrm{~m}$. The mass power summary of the communications system is given in Table 3.

TABLE 3. MASS/POWER SUMMARY OF COMMUNICATIONS SUBSYSTEM

\begin{tabular}{|l|c|c|}
\hline Component & Mass (kg) & Avg. Power (W) \\
\hline Receiver & 6.73 & 7.02 \\
Freq Synthesizer & 1.73 & 5.25 \\
Power Supply & 1.82 & 2.06 \\
Transmitter & 6.18 & 35.0 \\
Clock & 0.45 & 1.2 \\
Up-link Antenna & 1.5 & - \\
Down-link Antenna & 1.68 & - \\
TT\&C Antenna & 0.45 & - \\
Misc. & 1.33 & - \\
\hline
\end{tabular}

\section{Attitude Dynamics and Control Subsystem (ADCS)}

The attitude control subsystem keeps the antennas earth oriented and solar array sun oriented. It is accomplished, as discussed before, by rotation about pitch axis to keep the antennas oriented, and rotation about yaw axis to keep the 
solar array axis normal to sun vector and solar array rotation to keep solar panel area normal to sun rays. The first two rotations are accomplished by using the pitch and yaw reaction wheels and third rotation is achieved by the solar array drives. These rotations are periodic with orbit period. Therefore, reaction wheels are sized such that momentum desaturation is not required for these rotations. A pointing accuracy of \pm 0.5 degrees is achieved by the ADCS.

The ADCS is composed of three systems: the sensors, actuators and control electronics, as shown in Fig. 8. The component summary is given in Table 4. The sensors for the satellite consist of earth sensors, sun sensors and rate gyros. The earth sensor is a two axis conical horizon sensor capable of accurate sensing with a worst case pitch and roll error of \pm 0.7 degrees at $1204 \mathrm{~km}$ altitude. The yaw sensing requirement is fulfilled by four two-axis sun sensors. The sensors are mounted two each on the earth and anti-earth faces. The sun sensors will be able to provide yaw sensing with worst case error of +0.01 degrees. Three gyros are also included to provide redundant sensors.

TABLE 4. COMPONENT SUMMARY

\begin{tabular}{|c|c|c|c|c|c|}
\hline COMPONENT & MANUFACTURIER & $\begin{array}{l}\text { UNITS PER } \\
\text { S/C } \\
\end{array}$ & $\begin{array}{c}\text { UNIT Wl:IUilT } \\
(\mathrm{kg})\end{array}$ & $\begin{array}{c}\text { AVERAGE } \\
\text { DOWER (WATTS) } \\
\end{array}$ & HERTTAGE \\
\hline $\begin{array}{l}\text { DUAL-MODE } \\
\text { EARTH SENSOR }\end{array}$ & BARNES * & 1 & 3.77 & 4 & $\begin{array}{l}\text { MODIFIED } \\
\text { GPSIDMSP }\end{array}$ \\
\hline $\begin{array}{l}\text { COARSE SUN } \\
\text { SENSOR } \\
\end{array}$ & ADCOLE & 4 & 0.04 & 1 & INTELSAT VII \\
\hline $\begin{array}{l}\text { REACTION } \\
\text { WHEELSS } \\
\end{array}$ & HONEYWELL & 4 & 23 & $18 \mathrm{ea}$. & DMSP, TIROS \\
\hline $\begin{array}{l}\text { SPRING } \\
\text { RESTRAINT GYRO } \\
\text { ASSEMBLY }\end{array}$ & - & 1 & 1.2 & 19 & INTELSAT V \\
\hline $\begin{array}{l}\text { MIL STD } 1750 \\
\text { COMPUTER }\end{array}$ & BARNES * & 1 & 2.5 & 6 & MODIFED GPS \\
\hline
\end{tabular}

The reaction wheels are configured with three wheels along the roll, pitch and yaw axis and one wheel at a 45 degree angle to the others to provide redundancy. The $2-\mathrm{N}$ thrusters provide additional redundancy. They will also be used to desaturate the reaction wheels. The control electronic unit is a Barnes built Mil Standard 1750 microprocessor. It is light with low power requirements and meets all requirements. No redundancy is provided for this unit. Redundancy is indirectly provided by the ground control.

\section{Propulsion Subsystem}

The propulsion subsystem is a catalytic monopropellant hydrazine subsystem. It consists of four $38-\mathrm{N}$ and twelve $2-\mathrm{N}$ thrusters, four propellant 
and pressurant tanks, latching isolation valves, filters, pressure regulators, pressure transducers and lines made of titanium alloy. Figure 9 shows schematic diagram of the propulsion subsystem. The component mass breakdown is given in Table 5.

TABLE 5. PROPULSION SUBSYSTEM MASS BREAKDOWN

\begin{tabular}{|l|l|l|l|}
\hline Component & Manufacturer & Unit per s/c & Unit Mass (kg) \\
\hline Propellant Tank & TRW & 4 & 5.897 \\
2N-Thruster & Rocket Research & 12 & 0.319 \\
MR-50F & Company & & \\
38N-Thruster & Rocket Research & 4 & 0.735 \\
$\begin{array}{l}\text { MR-50F } \\
\text { Tubing and Valves }\end{array}$ & Company & - & 4.31 \\
\hline
\end{tabular}

Delta II upper stage puts the satellite in to $1203 \times 15742 \mathrm{~km}$ orbit. Final orbit, $1203 \times 14932 \mathrm{~km}$ is achieved by firing four $38-\mathrm{N}$ thrusters and four $2 \mathrm{~N}$ thrusters to reduce apogee. For attitude control, only $2-\mathrm{N}$ thrusters are used. As noted earlier, propellant required for three years mission is only $8 \mathrm{~kg}$ in comparison to propellant capacity of $140.0 \mathrm{~kg}$. This additional propellant can be used to supplement launch vehicle and or additional design life.

For the launch vehicle, the Delta II 7925 was selected. The upper stage consists of the Morton Thiokol Star 48B solid rocket motor, a cylindrical payload attach fitting, separation clamp, and spin table. The Delta II 3712 B attach fitting is the interface between the upper stage motor and the spacecraft. Spacecraft have inertia ratio greater than unity, resulting in passive spinstabilization. The combined upper stage with spacecraft, however, has inertia ratio less than unity, requiring nutation control system (NCS). Standard NCS used with upper stage is selected. It uses a single-axis Rate Gyro Assembly (RGA) to sense coning and a monopropellant hydrazine propulsion module to provide control thrust.

\section{Electric Power Subsystem}

The electric power subsystem provides electric power to all spacecraft subsystems throughout the mission. The subsystem, as shown in Figure 10, consists of solar arrays, batteries for eclipse period, and power control electronics. The spacecraft bus voltage is 28 volts. The shunt regulator will maintain the bus voltage at 28 volts during sunlight period and the battery charge/discharge unit is responsible for maintaining eclipse loads and charging the battery. Auxiliary voltage levels of 32 and 42 volts for use by the propulsion and attitude control subsystem will be generated from the 28 volt bus using dc-dc convertors.

\section{SOLAR ARRAY}

The solar array system consists of two flat panel arrays always maintaining a normal incidence to the sun. This is maintained by spacecraft rotation about yaw axis and solar array. GaAs solar cells have been selected. The solar cell 
effective area is $7.97 \mathrm{~cm}^{2}$ in a $2 \times 4 \mathrm{~cm}$ rectangular cell and an area mass of $0.086 \mathrm{~g} / \mathrm{cm}^{2}$ The cells have the following capabilities under AMO conditions: $I_{\mathrm{sc}}=232.0 \mathrm{~mA}, \mathrm{~V}_{\mathrm{oc}}=1014.0 \mathrm{mV}, \mathrm{I}_{\mathrm{mp}}=219.5 \mathrm{~mA}, \mathrm{~V}_{\mathrm{mp}}=876.0 \mathrm{mV}, \mathrm{P}_{\mathrm{mp}}=$ $192.3 \mathrm{~mW}$, and efficiency is $17.83 \%$.

The orbit apogee of $14933 \mathrm{~km}$ places the satellite in the lower portion of the Van Allen radiation belts. The resulting radiation effects on the solar cells are severe and represent the primary limiting factor of the satellite lifetime. The array structure consists of a substrate of $16 \mathrm{~mm}$ thick aluminum honeycomb core with a $0.13 \mathrm{~mm}$ aluminum facesheet. The face sheet thickness was selected by considering radiation shield effectiveness. The primary goal of the solar array design is to provide required EOL power while minimizing the mass of the arrays. A comparison was made of array mass using both $30 \mathrm{mil}$ and $20 \mathrm{mil}$ coverslips. Although 20 mil coverslips experience move radiation degradation and result in larger arrays, they still satisfy EOL power requirements with less mass than the 30 mil coverslips, and were therefore chosen for the design.

For an expected on orbit life of three years, the total radiation received in one $\mathrm{MeV}$ equivalent electrons for front and back exposure is $5.14 \mathrm{E}+15$ for voltage and $2.82 \mathrm{E}+15$ for current. This radiation exposure results in degradation of $10.8 \%$ for $V o c, 14 \%$ for $V_{m p}, 23 \%$ for $I_{s c}$, and $23.2 \%$ for Vmp. The advantages of the GaAs cells over silicon cells are low radiation degradation and higher power stability (or reduction) at high temperatures. The solar array design is given in Table 6 .

TABLE 6. SOLAR ARRAY DESIGN

\begin{tabular}{|c|c|}
\hline Cells in Series & 44 \\
\hline Cells in Parallel & 80 \\
\hline Total Number of Cells & 3520 \\
\hline $\begin{array}{c}\text { Total Array Area with Intercell } \\
\text { Spacing }\end{array}$ & $30307.2 \mathrm{~cm}^{2}$ \\
\hline $\begin{array}{c}\text { Panel Dimensions (2.5 cm boundary } \\
\text { on all sides) }\end{array}$ & $\begin{array}{c}0.487 \mathrm{~m} \mathrm{x} \mathrm{3.305} \\
\mathrm{m} \mathrm{x} 1.74 \mathrm{~cm}\end{array}$ \\
\hline Array Mass & $12.19 \mathrm{~kg}$ \\
\hline Worst Case Operating Temperature & $46.68^{\circ} \mathrm{C}$ \\
\hline Minimum Eclipse Temperature & $-117.88^{\circ} \mathrm{C}$ \\
\hline Maximum Power Oulput at 30.9 Volts & 504 Watts \\
\hline Minimum Power at EOL & 357.53 Watts \\
\hline
\end{tabular}




\section{Battery}

The batteries for eclipse power are 12 amp hour nickel-hydrogen batteries manufactured by Eagle Pitcher. This battery is provided in a two cell common pressure vessel (CPV) configuration. The battery voltage per CPV cell varies from 2.2 volts to 3.2 volts at full charge. For the bus configuration of a buck converter for constant current charge and a boost converter to maintain the line voltage, the number of CPV cells is limited to eight for the 28 volt bus. This gives a maximum battery voltage of 25.6 volts and a minimum of 17.6 volts.

The battery requirements are obtained from the eclipse load requirement of 140 Watts, with the boost convertor efficiency of $85 \%$, the actual power supplied by the battery during the eclipse period will be 164 Watts. The maximum eclipse period is 37 minutes. For the three year projected mission lifetime, the satellite will experience a maximum of 4500 eclipse periods. The charge rate chosen for this satellite is $\mathrm{C} / 7$. At this rate, the charging current is 1.7 amps, and the maximum power required for charge, including charger efficiencies, is 52.5 Watts.

\section{Power Control Electronics}

The power control electronics is responsible for providing a fully regulated bus at 28 volts. This regulation is accomplished by employing a shunt regulator for periods when the solar array is powering the spacecraft and by using a booster regulator for periods when the battery system is supplying the power.

The detailed mass breakdown for electric power subsystem is shown in Table 7. The available power from the solar array as a function of orbit time is shown in Figure 11. The difference between maximum and minimum power at any time is the uncertainty in power prediction and launch date. The variation of power as a function of orbit time is due to radiation degradation, change in array temperature, and variation in solar intensity. The intensity is maximum at perihelion, and minimum at aphelion. This results in peaks at perihelion and valleys at aphelion.

TABLE 7. ELECTRIC POWER SUBSYSTEM MASS BREAKDOWN

\begin{tabular}{|l|c|}
\hline Component & Mass (kg) \\
\hline Solar Arrays & 12.19 \\
Batteries & 7.12 \\
Wire Harness & 9.15 \\
Mechanical Integration & 4.2 \\
Solar Array Drive Electronics & 2 \\
Solar Array Drive & 8 \\
Power Electronics & 4 \\
Shunt Resistor Bank & 1.89 \\
\hline
\end{tabular}

\section{Telemetry, Tracking and Command Subsystem}

The TT\&C subsystem has three primary functions: up-link commands to spacecraft subsystems, down-link telemetry from spacecraft subsystems, and 
autonomous control for period the satellite is not in communications with the mid-latitude ground station (MLG). The schematic diagram is shown in Figure 12.

The TT\&C subsystem has tow basic components: Remote Telemetry Unit (RTU) and Remote Command Unit (RCU). The RTU is essentially the interface between the telemetry antenna and the remote command unit. It performs all the function of a transponder, including RF distribution the single antenna, modulation, demodulation and encoding/decoding of the telemetry data. The RTU up-link is at $350 \mathrm{MHz}$ and its down-link is $253 \mathrm{MHz}$. The information is transmitted at a 1200 bit per second data rate, but it is encoded using a linear block code resulting in a 2400 bit per second transmission rate. Its mass is 7.57 $\mathrm{kg}$ and average power required 2.25 watts.

The RCU performs satellite control operations through the use of coded algorithms resident in memory. The RCU formats and relays telemetry to the RTU and acts on this telemetry in performing autonomous control of the satellite. The RCU also receives command signals from the RTU and performs these operations which have priority over on-board generated commands. The mass of RCU is $5.81 \mathrm{~kg}$ and average power consumption is $0.12 \mathrm{~W}$.

\section{Structure Subsystem}

The structure provides mechanical support to all equipment and is designed for launch constraints of Delta II launch with three satellite in a stacked configuration.

For the stacked configuration two interface alternatives were considered. First, each spacecraft attached directly to launch vehicle through separate attach fitting. Second, only bottom spacecraft connected to launch vehicle. In the second configuration, bottom spacecraft structure will support launch loads for all the three structure. Separate structural design for each spacecraft was also considered. Taking into considerations complexity and cost, it was decided to attach only the bottom spacecraft to the launch vehicle and identical structural design for all spacecraft, resulting in structural over-design for the middle and the upper spacecraft.

The majority of the equipment mass is located on the east and west panels which are designed to withstand $30 \mathrm{~g}$ 's and have fundamental frequency above 25 Hz. Load paths are provided to the central cylindrical assembly by means of panels attached to the North and South ends of the equipment panels. These support panels are also used to secure the four propellant tanks for axial loads. Lateral load support for the provided by struts attached to the top and bottom of the tanks and to the central cylindrical assembly.

The design loads are 1.5 times the flight limit loads. Margin of safety of $10 \%$ is assumed. The east/west equipment panels are aluminium honeycomb sandwich with aluminium facesheets. Core thickness is $9.525 \mathrm{~mm}$ and face sheet thickness is $0.912 \mathrm{~mm}$.

Fundamental lateral fundamental frequency is $42.71 \mathrm{~Hz}$ for the spacecraft and $6.22 \mathrm{~Hz}$ for the three stacked configuration. The staked frequency is below $15 \mathrm{~Hz}$, which is a minimum design requirement for the Delta II. Therefore, 
coupled spacecraft/launch vehicle dynamic analysis is required to determine the effect of this lower frequency on launch loads. This may require redesign of the central assembly.

\section{Thermal Control Subsystem}

The function of the thermal control subsystem is to maintain the spacecraft temperatures within the operating temperature limits of its components. Passive thermal control techniques are generally used. East and West surfaces, which receive only albedo and earth radiated flux but no solar flux, are used for radiators. Each surface has radiator of optical solar reflector of size $0.9 \times 0.7$ $\mathrm{m}$. The equipment panel is of aluminum honeycomb construction with aluminum heat sinks as required. Multilayer insulations (MLI) are used extensively. Low temperature applications use MLI with outside layers of aluminum kapton; and hot temperature locations, such as thrusters, use MLI with outside layers of titanium kapton.

Heaters are used to maintain temperature of certain equipment (tanks, lines, valves, etc.) above minimum operating temperature; and to replace heat of certain equipment, such as communications transponder, when they are turned off. Thrusters have their own heaters for their catalytic beds.

\section{LAUNCH SEQUENCE}

All three satellites, as shown in Fig. 13, will be launched simultaneously on a single Delta/Star 48 launch vehicle. The launch sequence is shown in Figure 14. The launch will take place from the Kennedy space Center, and will place the three satellites initially into a $1204 \times 15729 \mathrm{~km}$ orbit at 63.4 inclination. The launch vehicle upper stage will provide spin stabilization during the period the spacecraft are attached to it by using active nutation control. As each satellite separates from the upper stage, it will be spinning about a stable axis, eliminating the need for active nutation control. In this initial orbit, the spacecraft will acquire the sun, deploy the solar arrays, and then acquire the earth, bringing into three-axis stabilized configuration. Next, orbit correction is made by using the four $38-\mathrm{N}$ thrusters. This burn will place this satellite into the $1204 \times 14933 \mathrm{~km}$ mission orbit. Since the mission orbit has a 4.8 hour period compared to the 5.0 hour period of the launch orbit, the second spacecraft will be aligned for insertion 8 orbits later, with the final spacecraft aligned for insertion 8 orbits later, with the final spacecraft aligned following an additional 8 orbits. This sequence will put the entire plane of satellites in position 80 hours after the initial spacecraft is inserted into the mission orbit. This period will allow accurate determination of orbit parameters.

\section{CONCLUSIONS}

This paper presents preliminary design of a high latitude communications satellite. The spacecraft configuration was selected after performing trade-offs of several possible configurations. The spacecraft subsystems can be further improved by performing detailed analyses. Some of the subsystems are overdesigned for the mission. As an example, for three years mission the minimum 
propellant required is $8 \mathrm{~kg}$ and the propulsion subsystem is designed for $140 \mathrm{~kg}$ propellant. This was done because of uncertainty at the early stage of design in the propellant requirement for station-keeping. Redesign of the spacecraft for minimum required propellant will result in significant reduction in the mass of the propulsion and structure subsystems. Design of a spacecraft

bus for low earth orbit is a continuing spacecraft design project at the Naval Postgraduate School.

\section{FIGURES}

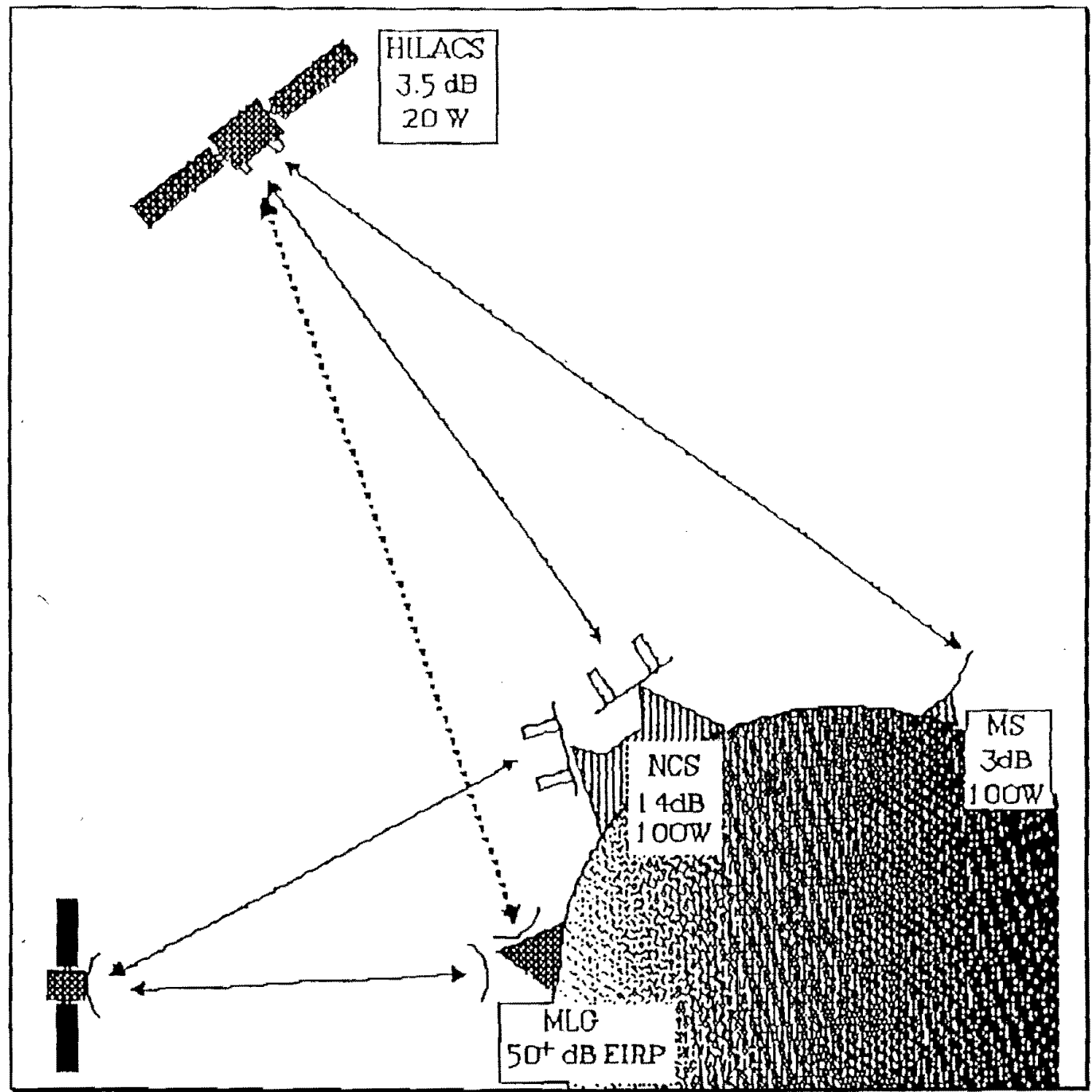

Fig. 1. Satellite Mission 

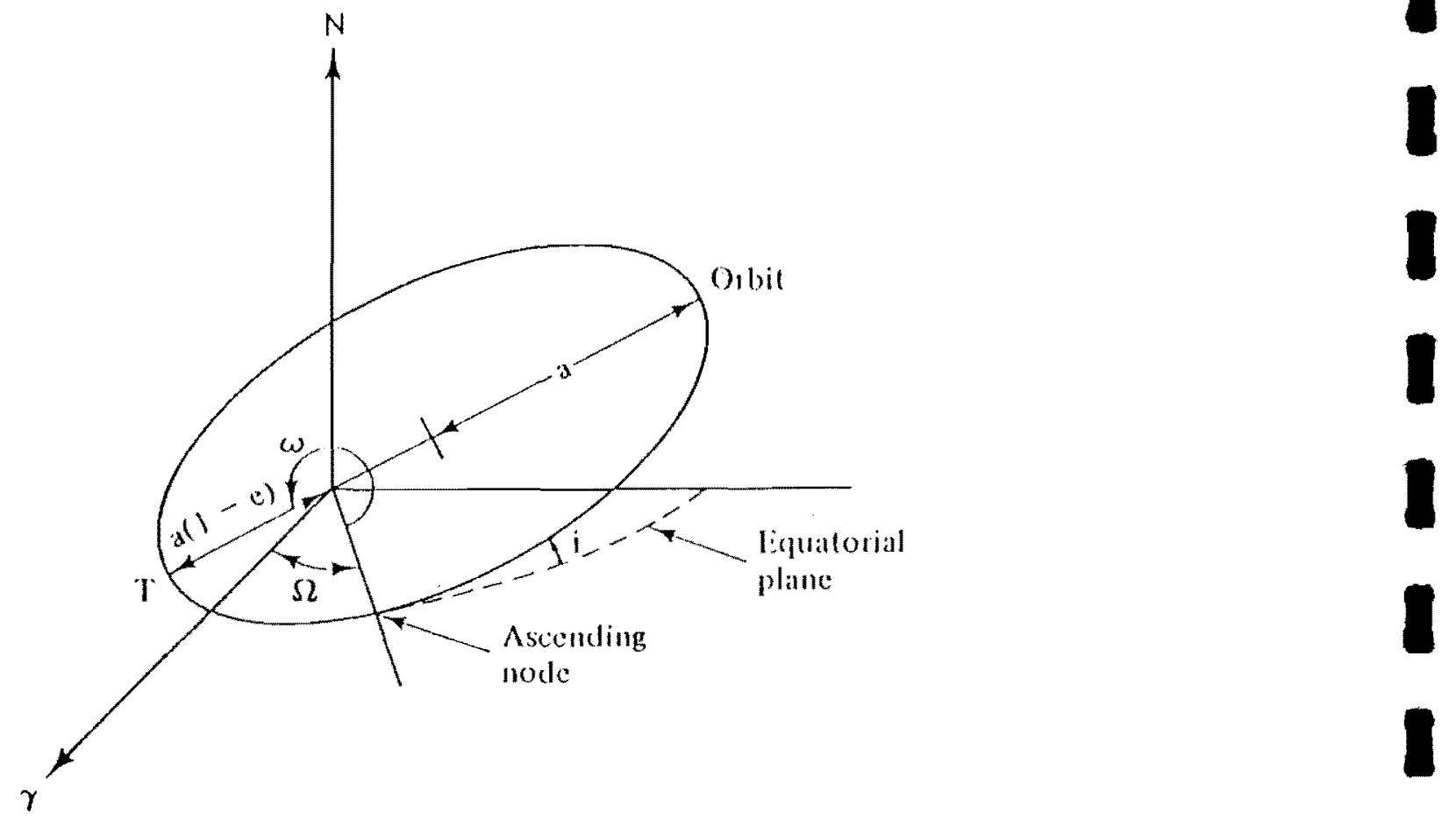

Fig. 2. Orbit elements

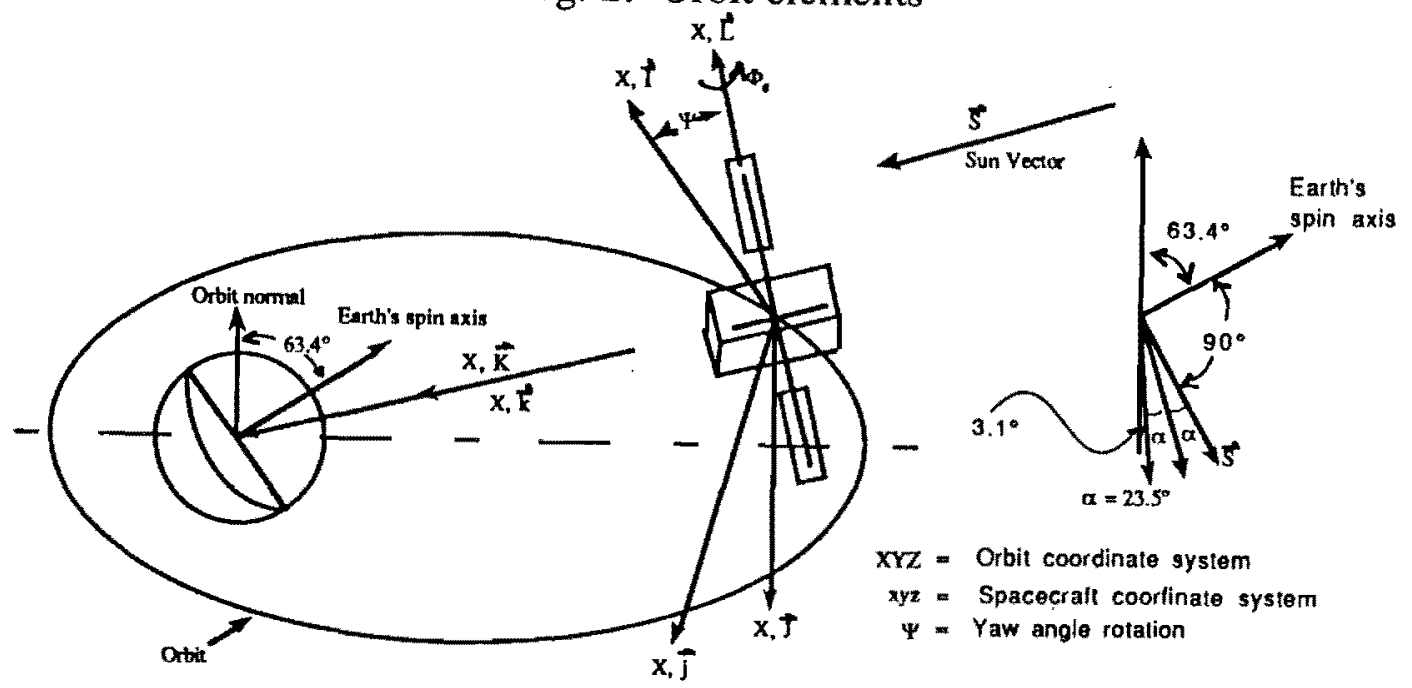

Fig. 3. Spacecraft Configuration 


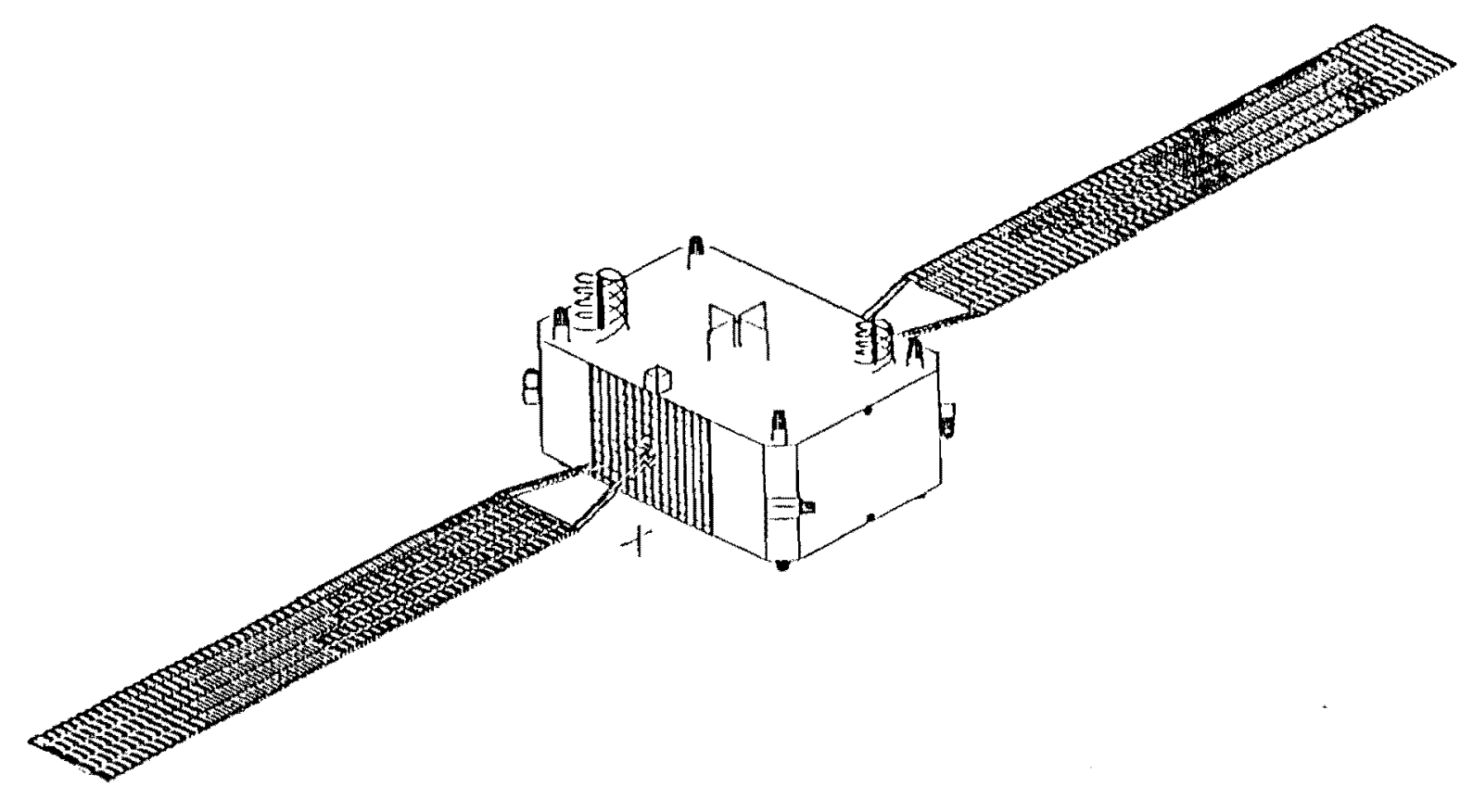

Fig. 4. Spacecraft in Deployed Configuration

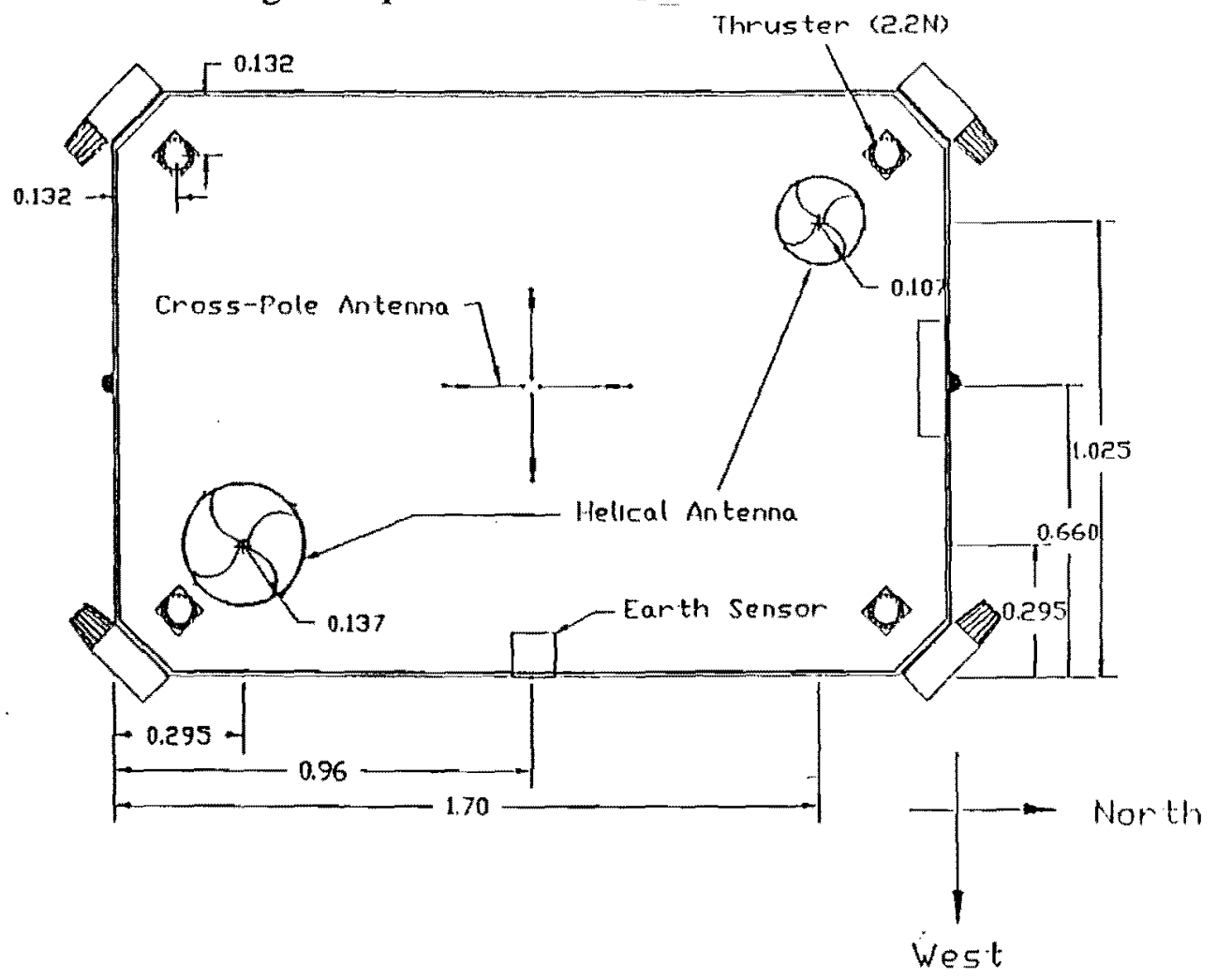

Fig. 5. Earth-Facing Panel 


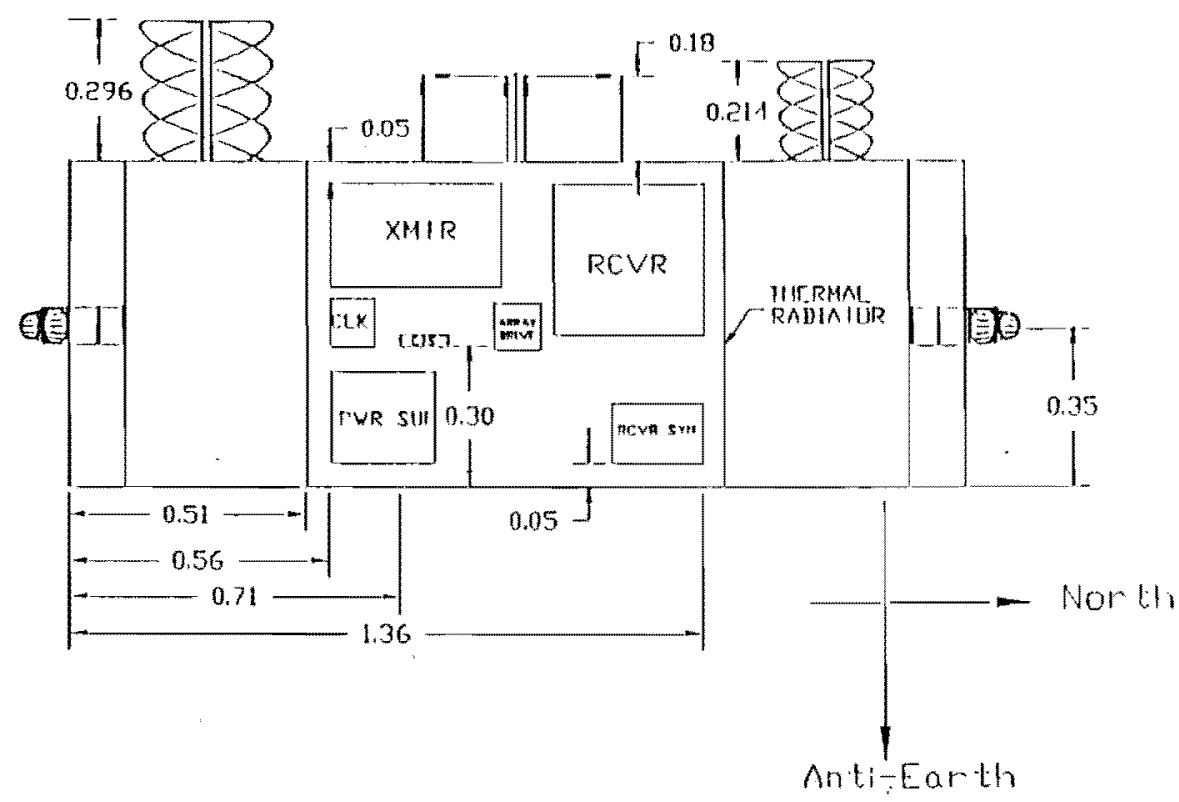

Fig. 6. West-Facing Panel

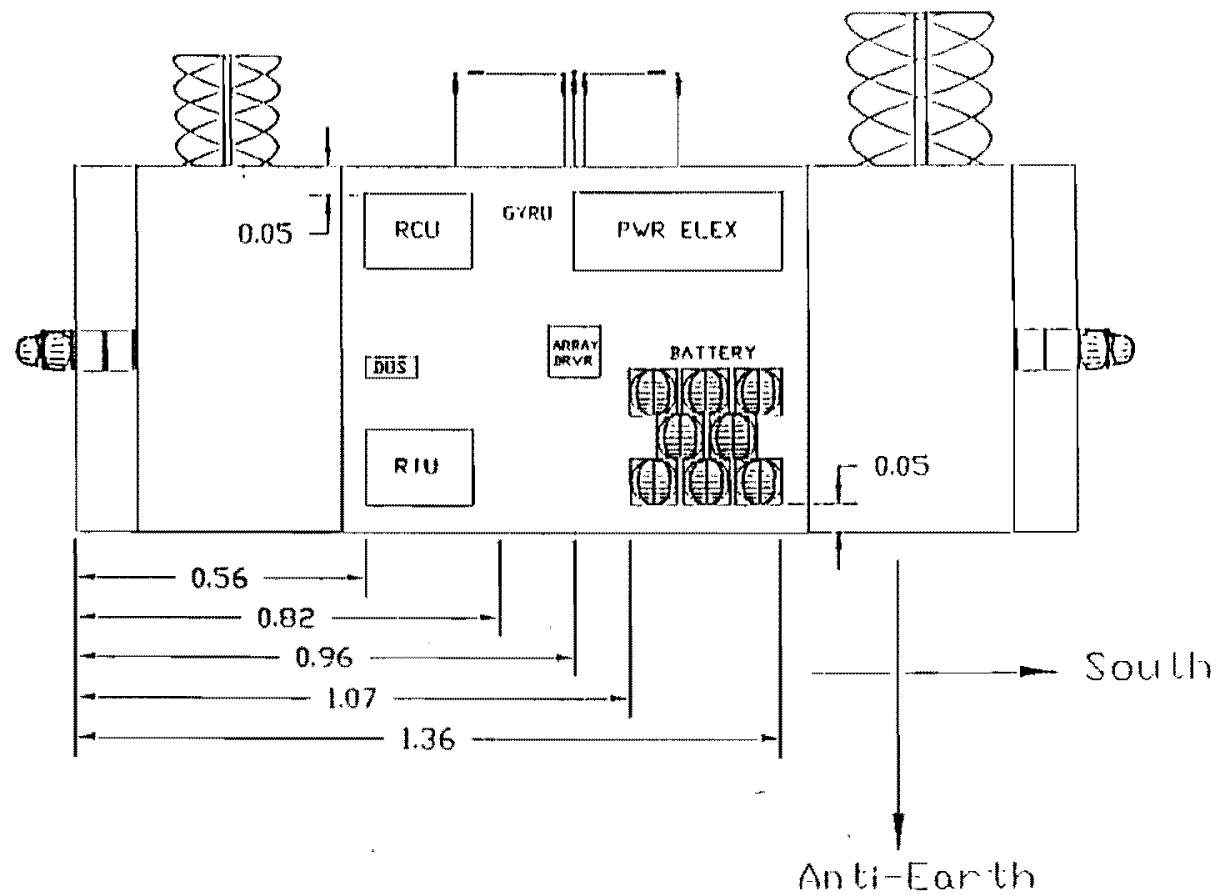

Fig. 7. East-Facing Panel 


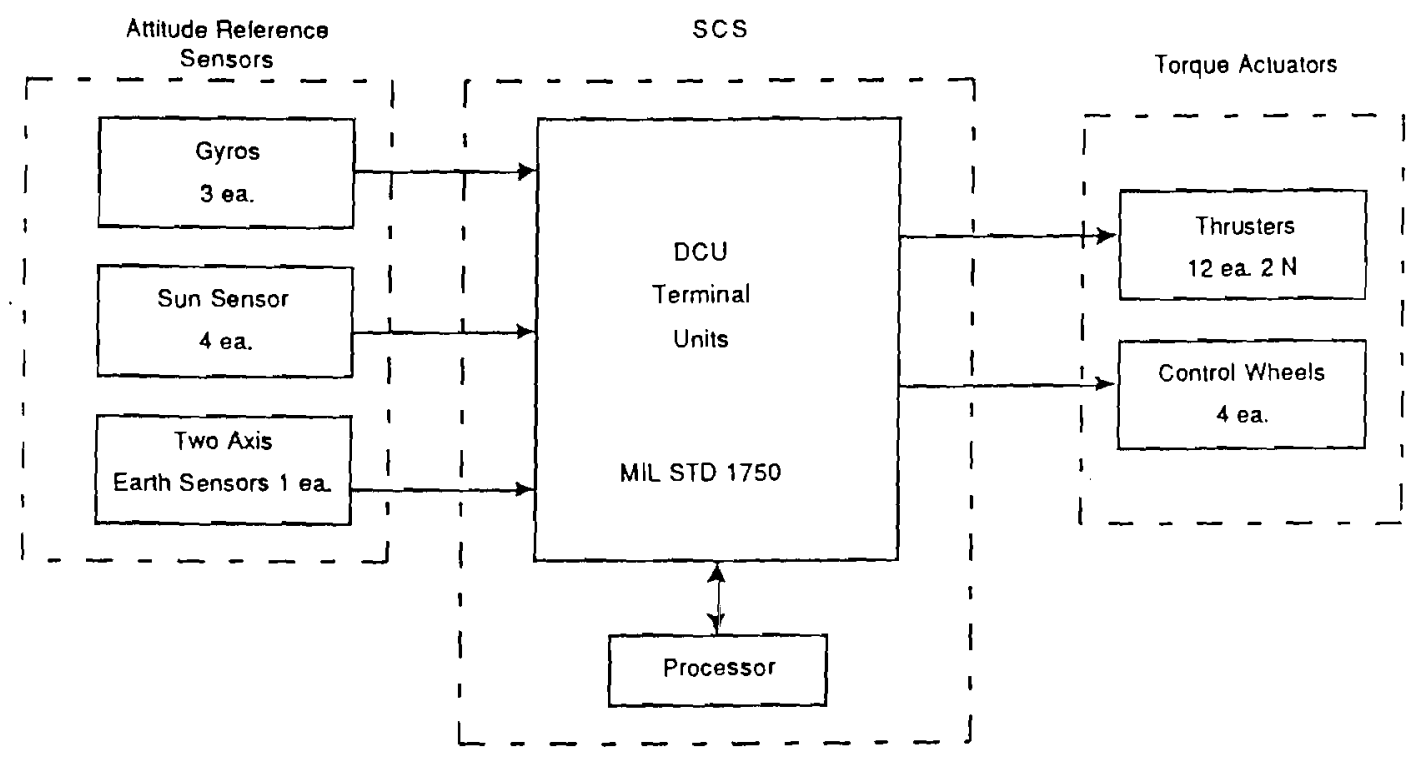

Fig. 8. ADCS Schematic Diagram

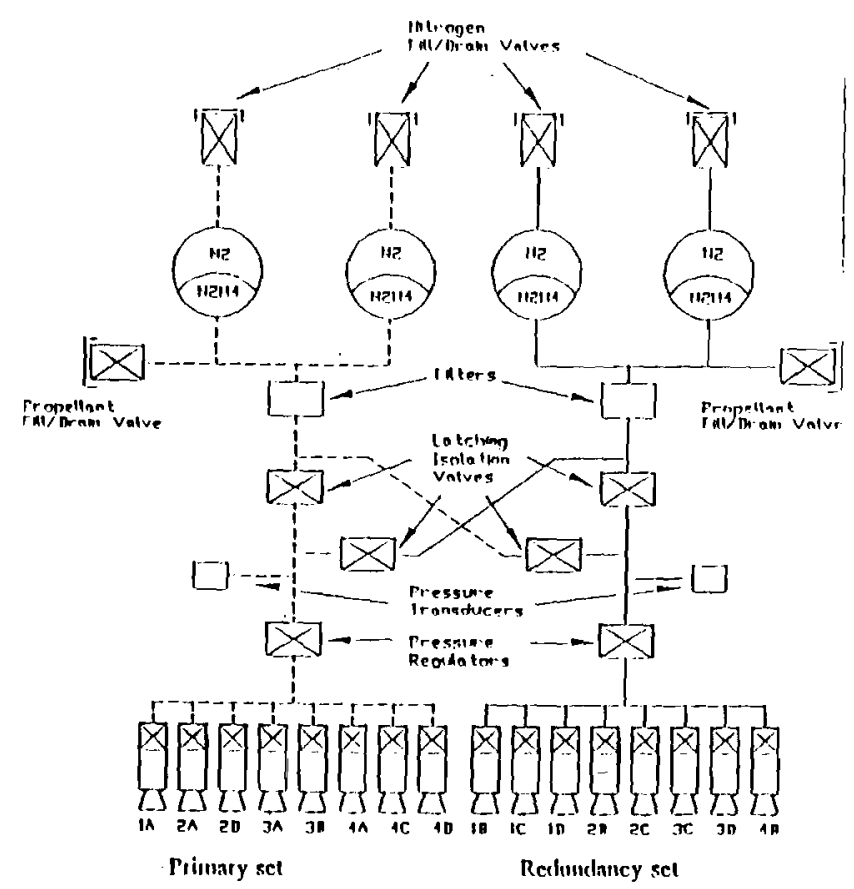

Fig. 9. Schematic Diagram of Propulsion Subsystem 


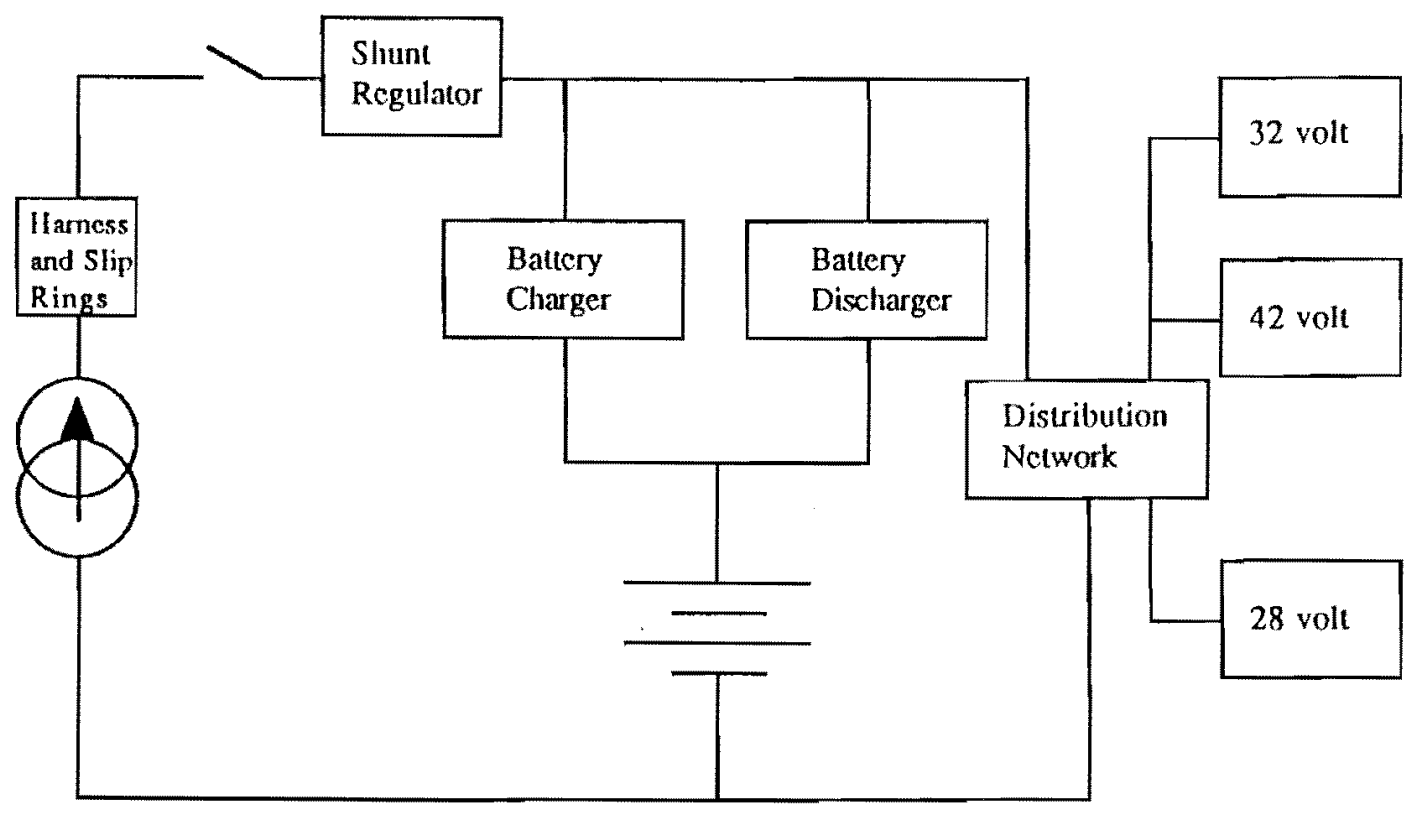

Fig. 10. Schematic Diagram of Electric Power Subsystem

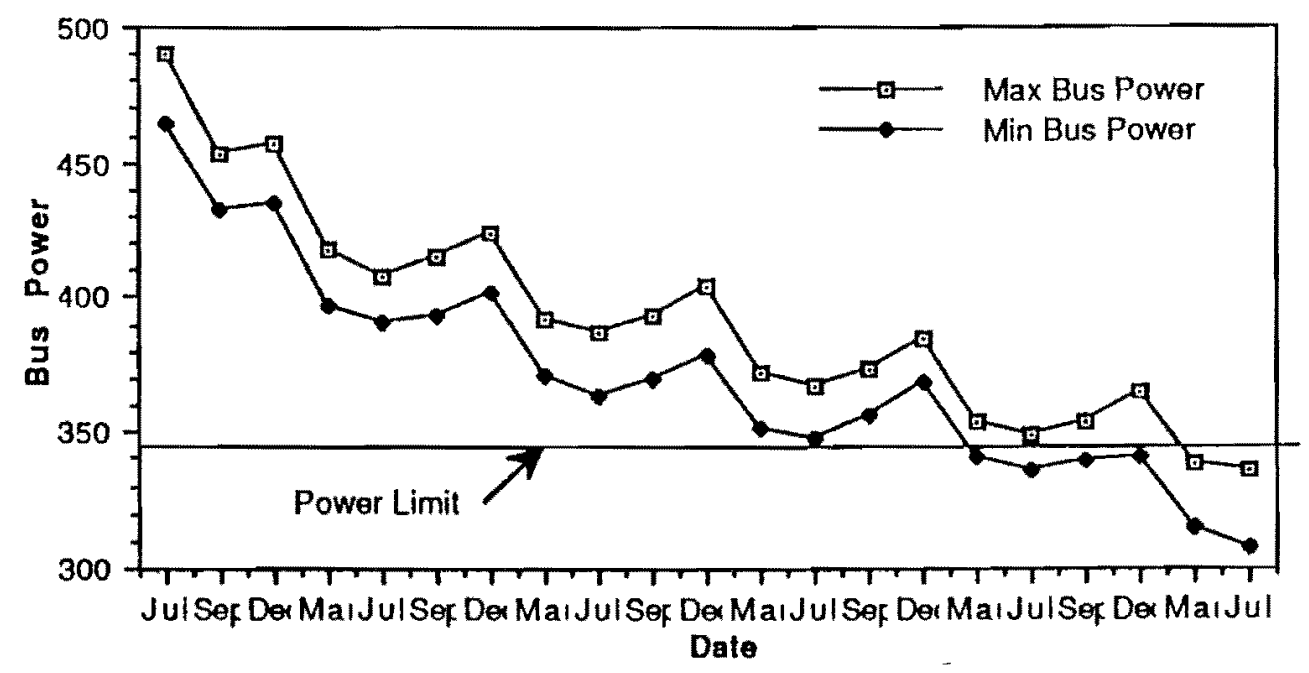

Fig. 11. Power vs. Time in Orbit 


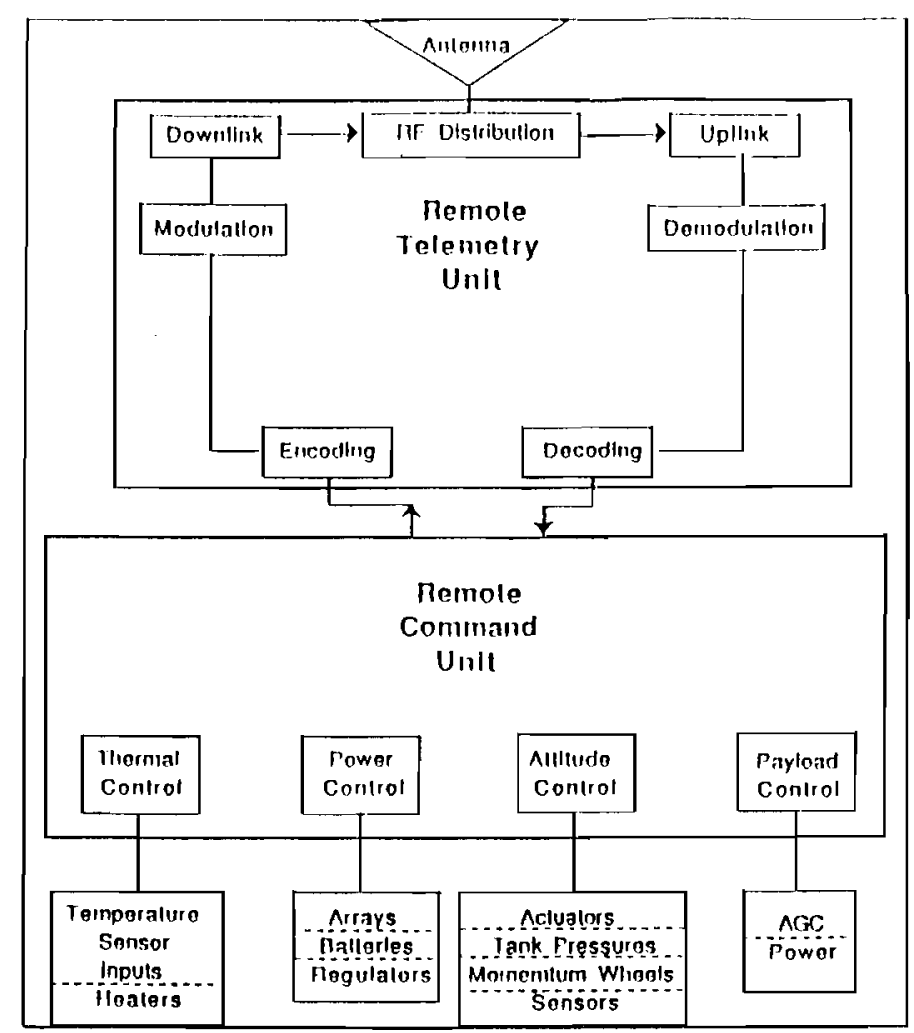

Fig. 12. Schematic Diagram of TT\&C Subsystem

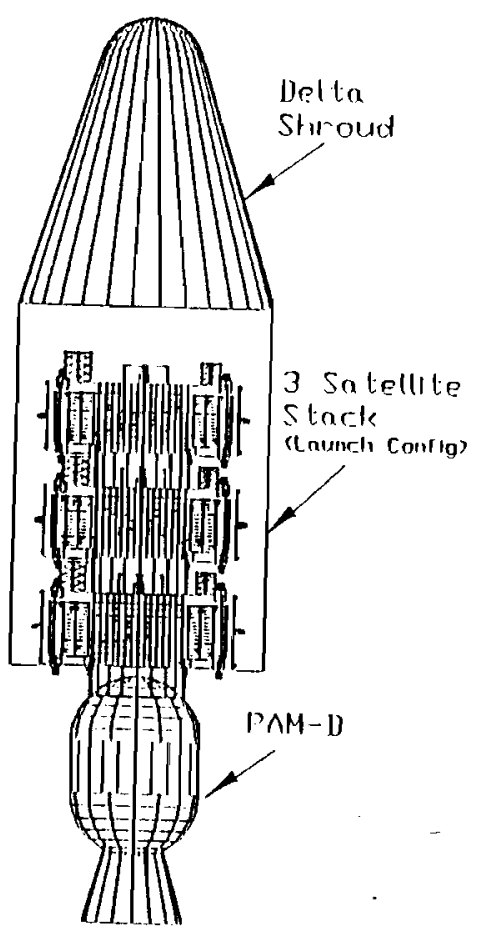

Fig. 13. Launch Configuration 


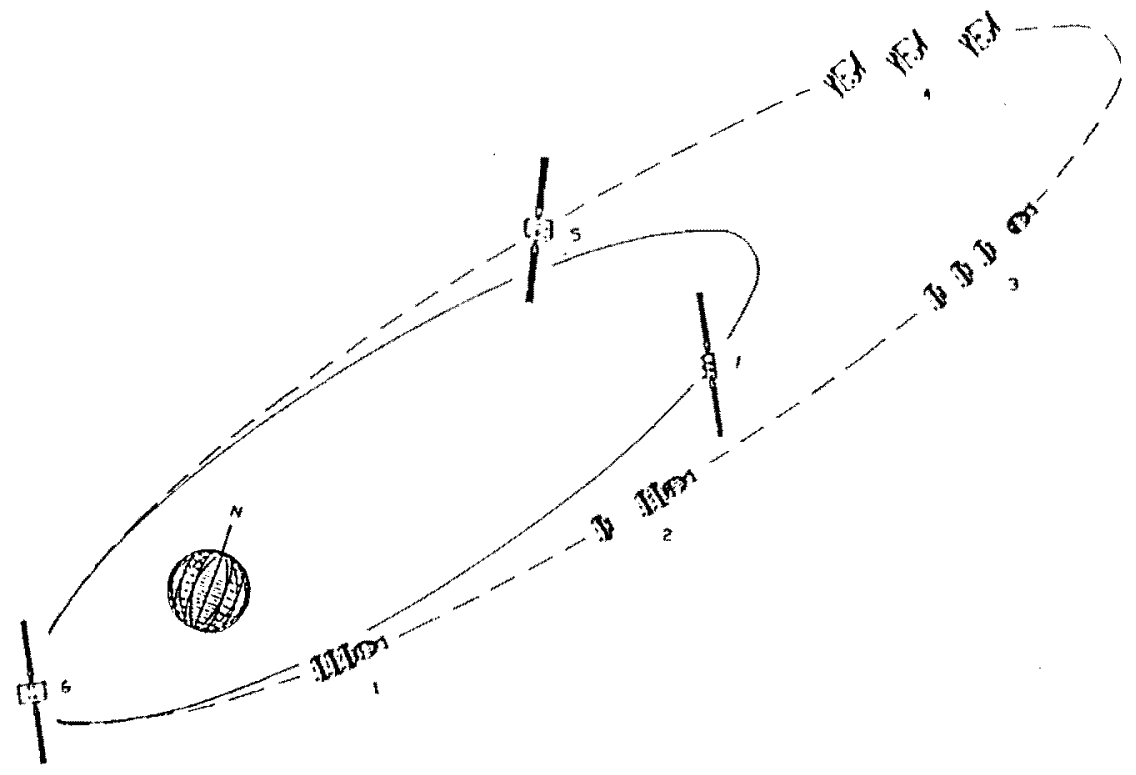

Fig. 14. Launch Sequence

\section{ACKNOWLEDGEMENTS}

The work presented in this paper was performed under spacecraft design project course at the Naval Postgraduate School by the following students: Carl Josefson, Jack Myers, Mike Cloutier, Steve Paluszek, Gerry Michael, Dan Hunter, Dan Sakoda, Wes Walters, Dennis Johnson, Terry Bauer, Charlie Racoosin, and Butch Lugtu. This project was also sponsored by the NASA/Universities Space Research Association Advanced Design Program. The students received support from the faculty at the Naval Postgraduate School (NPS), Naval Research Laboratory (NRL), and Jet Propulsion Laboratory (JPL). Following personnel in particular, contributed to the success of the project: Profs. Kolar, Adler, Myers and Kraus from NPS; Mike Brown, Shannon Coffey, Chris Garner, Marv Levinson, and Tom Kawecki from NRL; and Mr. Burke and Dr. Kwok from JPL.

\section{REFERENCES}

1. "Spacecraft Design Project, High Latitude Communications Satellite," Naval Post Graduate School, December 1989

2. NASA Solar Cell Array Design Handbook, Vol. I and II

3. "Delta II User's Manual," McDonnell Douglas Astronautics Corporation 
4. B. N. Agrawal, Design of Geosynchronous Spacecraft, Prentice-Hall, Inc. Englewood Cliffs, NJ 1986

5. C. C. Kilgus, "Resonant Quadrifilar Helix Design," Microwave Journal, Vol. 13, December 1970 